\title{
Giving in the face of risk
}

\author{
Elena Cettolin ${ }^{1}$ - Arno Riedl ${ }^{2}$ - Giang Tran ${ }^{3}$
}

Published online: 3 February 2018

(c) The Author(s) 2018. This article is an open access publication

\begin{abstract}
Decisions about how to share resources with others often need to be taken under uncertainty regarding its allocational consequences. Although risk preferences are likely important, existing research is silent about how social and risk preferences interact in such situations. In this paper we provide experimental evidence on this question. In a first experiment givers are not exposed to risk while beneficiaries' final earnings may be larger or smaller than the allocation itself, depending on the realized state of the world. In a second experiment, risk affects the earnings of givers but not of beneficiaries. We find that individuals' risk preferences are predictive for giving in
\end{abstract}

The research documented in this paper was partly financed by the Oesterreichische Nationalbank (project number 11429) and also received financial support from the Netherlands Organization for Scientific Research (NWO) (project number 400-09-451).

Electronic supplementary material The online version of this article (https://doi.org/10.1007/s11166-017-9270-2) contains supplementary material, which is available to authorized users.

Arno Riedl

a.riedl@maastrichtuniversity.nl

Elena Cettolin

e.cettolin@uvt.nl

Giang Tran

giang.tran@maastrichtuniversity.nl

1 Department of Economics, Tilburg School of Economics and Management, Tilburg University, P.O. Box 90153, 5000 LE Tilburg, The Netherlands

2 CESifo, IZA, Netspar, Department of Economics (AE1), School of Economics and Business, Maastricht University, P.O. Box 616, 6200 MD Maastricht, The Netherlands

3 Department of Economics (AE1), School of Economics and Business, Maastricht University, P.O. Box 616, 6200 MD Maastricht, The Netherlands 
both experiments. Increased risk exposure of beneficiaries tends to decrease giving whereas increased risk exposure of givers has no effect. We propose a simple nonlinear generalization of a model allowing for other-regarding preferences, ex-post and ex-ante fairness, and risk aversion. We find some support for it in our data when risk is on the beneficiaries' side but less so when risk is on the givers' side. Our results point to the importance of the further development of models of social preferences that also incorporate risk preferences.

Keywords Fairness · Uncertainty $\cdot$ Risk $\cdot$ Other-regarding preferences $\cdot$ Social preferences $\cdot$ Risk preferences $\cdot$ Experiment

JEL Classification C91 $\cdot$ D03 - D64 - D81

\section{Introduction}

A large empirical literature shows that individuals are willing to sacrifice some of their own material interests to the advantage of others, even if those people are anonymous. Interestingly, this evidence has almost exclusively been gathered for situations where the decision to give is made under full information about its distributional consequences. ${ }^{1}$ Arguably, this information condition is not often met in reality. For example, when donating money to charities there is usually no guarantee about how exactly beneficiaries will benefit (e.g., due to environmental and organizational risks or due to uncertainty about the marginal utility to the beneficiary of an extra dollar of donation). Not only potential beneficiaries, but also givers themselves are often exposed to uncertainty regarding the exact consequences of resources kept. Unless these resources are immediately consumed, welfare effects can substantially vary depending on the giver's exposure to health, safety, or financial risks.

The question is whether such irresolvable uncertainty influences giving behavior, and if so how and through which channels? Are people more or less generous when the beneficiaries' or their own personal situation is uncertain? What are the determining factors of giving when final outcomes are risky? Intuitively, social preferences as well as individual risk preferences will affect giving in the face of risk. While there is an extensive literature on the role of social preferences under certainty (Camerer 2003; Engel 2011) and a smaller, growing, literature on ex-post and ex-ante perspectives on fairness under risk (e.g., Brock et al. 2013; Cappelen et al. 2013), to date the role of risk preferences remains unstudied. In this paper we present, to the best of our knowledge, first evidence on how own risk preferences and perceived risk preferences of others affect generosity in situations where risk cannot be resolved.

We present the results of two stylized experiments designed to investigate how exogenous outcome uncertainty on respectively the givers' and beneficiaries' side affects giving behavior. The experiments are based on the standard dictator game

\footnotetext{
${ }^{1}$ See Engel (2011) for a meta study on dictator games under certainty. The few recent exceptions taking uncertainty into account will be discussed below.
} 
(Forsythe et al. 1994) and vary riskiness in a controlled way. In the first experiment, givers can make a transfer to beneficiaries who are exposed to various forms of risk (we will refer to this experiment as RISK-B). Importantly, the size of the transfer has to be decided before risk is resolved, and the beneficiaries' final earnings can be smaller or larger than the transfer itself, depending on the realized state of the world. In a second experiment we study giving behavior in mirror-image situations when givers' final outcomes are risky and known only after the allocation decision, while beneficiaries' outcomes are certain (we refer to this experiment as RISK-G).

In both experiments participants are matched in pairs and randomly assigned the role of either giver $(\mathrm{G})$ or beneficiary $(B) .^{2}$ To increase salience, both $\mathrm{G}$ and $\mathrm{B}$ individually work on a real effort task by which they earn money that is deposited in a joint account of the pair. After the task is completed, $G$ is asked to divide the deposited money between himself and B, in several allocation problems characterized by different degrees of risk. In experiment RISK-B, G always earns exactly what he keeps while the final earnings of B are risky. Specifically, in each allocation problem B's final earnings are either larger or smaller than the allocation itself, but are in expected value equal to it. Conversely, in experiment RISK-G, G's final earnings are risky and in expectation equal to the share he keeps for himself, while B earns exactly what is allocated to her. In order to examine how risk preferences affect givers' allocation decisions, we elicit participants' own attitude to risk as well as their beliefs about the risk attitude of others, in an incentive compatible way in both experiments.

Our results show that in both experiments the risk preferences of givers are predictive for their allocation choices. In RISK-B, givers' risk aversion is positively correlated with the shares allocated to beneficiaries, indicating that givers, on average, compensate beneficiaries' exposure to risk by taking into account their own attitudes toward risk. In RISK-G, givers' risk aversion is negatively correlated with their giving behavior, suggesting that the more risk averse they are, the more they compensate themselves for their exposure to risk. In both experiments givers' own risk attitudes are positively correlated with their beliefs about beneficiaries' risk attitudes, but the latter have basically no predictive power. Thus, givers' own risk preferences appear to be important determinants of their generosity under risk.

These effects of individual risk preferences on generosity are robust to controlling for the riskiness of the allocation problem. Riskiness has an independent effect on giving behavior, which differs between experiments. In RISK-B allocations to the beneficiary are significantly negatively correlated with the riskiness of the beneficiary's earnings, especially when risk is large. In contrast, in RISK-G, no correlation between giving and the riskiness of the giver's earnings is found.

To date there is no model available that incorporates both social preferences and risk preferences in a canonical way. We therefore did not have any clearly formulated hypotheses prior to the study. However, after having presented the results, we discuss a simple non-linear generalization of a model allowing for other-regarding

\footnotetext{
${ }^{2}$ Throughout the paper we refer to beneficiaries as female and givers as male. In the experiment genders were mixed over roles.
} 
preferences, ex-ante and ex-post fairness concerns, and risk aversion and link it to observed behavior.

Saito (2013) extended the popular other-regarding preferences model of Fehr and Schmidt (1999) to analyze ex-ante and ex-post motives of fairness when outcomes are risky. ${ }^{3}$ His model retains (piece-wise) linearity in own and others' earnings and is therefore silent about the potential effect of risk aversion on allocation decisions. We propose a combination of Neilson's (2006) non-linear generalization of Fehr and Schmidt (1999) with Saito's (2013) approach to allow for other-regarding preferences and risk aversion. Using this simple extension we find that behavior in RISK-B is surprisingly consistent with the model's predictions. This is however much less the case for behavior in RISK-G, indicating the importance of the further development of models of other-regarding preferences that also incorporate risk preferences.

Our paper contributes to the small but growing experimental literature that investigates decision situations under risk where social preferences may matter. A few papers explored whether people care about ex-ante (procedural) or ex-post (outcome) fairness or both. Bolton et al. (2005) have been the first to experimentally test procedural fairness and find that people do care for fair procedures. Brock et al. (2013) conduct dictator game experiments with risky outcomes to explore whether ex-post or ex-ante fairness considerations are more important. Their results suggest that both motives contribute to explain dictators' allocation behavior, and that behavior in a standard (risk free) dictator game correlates with giving in risky situations.

In Krawczyk and Lec (2010) subjects can share chances to win a prize with an anonymous other in lotteries that are either correlated or independent. They find that dictators give away more chances in the latter case and that motives other than simple inequity aversion are at play when individuals share chances. Cappelen et al. (2013) analyze the allocations of both non-involved subjects and dictators in situations where inequalities in output are the result of antecedent choices under risk. They observe that, although many participants favor some redistribution ex-post, the allocation decisions of most dictators and non-involved subjects are exclusively motivated by the consideration of ex-ante opportunities. ${ }^{4}$

Our study differs in several aspects from those discussed above. Most importantly, to our knowledge, none has directly addressed the role of individual risk preferences on giving behavior when risk cannot be resolved. We elicit participants' risk preferences and beliefs about the preferences of others in a task free from social aspects.

\footnotetext{
${ }^{3}$ For another popular outcome based model of other-regarding preferences, see Bolton and Ockenfels (2000), and for extensions of such models incorporating risk prior to Saito (2013), see Trautmann (2009) and Krawczyk (2011). All these models (implicitly) assume risk-neutrality.

${ }^{4}$ More remotely our paper is also related to studies that investigate how non-involved individuals (spectators) allocate money or chances to individuals in need (Rohde and Rohde 2015; Andreoni et al. 2016; Cettolin and Riedl 2017). Rohde and Rohde (2015) find that spectators are averse to ex-ante inequality and individual risk, while they seek ex-post inequality and collective risk. Andreoni et al. (2016) find that uninvolved individuals exhibit time-inconsistency in their social preferences, in the sense that they can hold incompatible ex-ante and ex-post views of fairness. Cettolin and Riedl (2017) find that spectators are highly heterogeneous in what they consider to be a just allocation under risk, but that on average they tend to allocate less to individuals who are more exposed to risk.
} 
In addition, we systematically vary the potential dispersion of both the beneficiary's and the giver's final outcomes in a way that allows us to investigate (i) how giving responds to the riskiness of the situation and (ii) how identical risk on the beneficiary's and the giver's side, respectively, affects giving behavior. Together, these design elements allow us to relate giving behavior to an individual's own and believed risk preferences as well as to the riskiness of own and others' earnings.

The remainder of the paper is organized as follows. In Section 2 the experimental design is described in detail. Results are presented in Section 3 and in Section 4 we relate them to theoretical predictions of our proposed model and also report some additional results for allocation problems under ambiguity. In Section 5 concluding remarks are drawn. The experiment instructions are provided in the Electronic Supplementary Material (ESM).

\section{Experiment design}

Both experiments, RISK-B and RISK-G, are computerized and consist of three parts. In what follows the different parts are described in detail. We start with Part 1, which can be divided into two sub-parts.

Part 1.a: Real effort task After all participants have taken a seat in their designated computer station, they are informed that the experiment consists of three parts. The instructions for the first part are then distributed and read out aloud by the experimenter. At the beginning of the first part participants are randomly paired. One participant is assigned the role of giver $(\mathrm{G})$ and the other the role of Beneficiary (B) ${ }^{5}$ Roles are fixed throughout the experiment and subjects are informed about this.

Thereafter all participants work on a real effort task, the so-called slider task (Gill and Prowse 2012). On the computer screen 32 sliders on horizontal bars are displayed. Each slider can be moved with the mouse for an unlimited number of times and the position of a slider is displayed to the right of the bar with a number between 0 and 100. A slider is correctly positioned when the number 50 appears, that is when the slider is positioned exactly in the middle of the bar. Productivity is measured by the number of sliders positioned at 50 in 6 minutes' time. During the task subjects view their own actual productivity and the amount of time remaining.

The slider task is easy to explain and to understand, is identical across repetitions and has no scope for guessing. The task is incentivized by awarding $€ 0.25$ for each correctly positioned slider, so that each subject can earn up to $€ 8$. After the time for the task has expired, $\mathrm{G}$ and $\mathrm{B}$ in the same pair view each others' productivity and the total amount of money generated, which is deposited in a joint account of the pair. We chose this procedure to increase salience (List 2007; Bardsley 2008). Furthermore, we calibrated the difficulty of the task such that maximum productivity is relatively

\footnotetext{
${ }^{5}$ In the experiment subjects are assigned the neutral labels A and B.
} 
Table 1 Allocation problems in RISK-B and RISK-G

\begin{tabular}{llllll}
\hline & \multicolumn{2}{l}{ RISK-B } & & RISK-G & \\
\cline { 2 - 3 } \cline { 5 - 6 } Problem & G's earnings & B's earnings & & G's earnings & B's earnings \\
\hline 1-Certainty & $X-x_{1}$ & $x_{1}$ & $X-x_{1}$ & $x_{1}$ \\
2-Risk & $X-x_{2}$ & $0.5: 1.5 \cdot x_{2}, 0.5 \cdot x_{2}$ & $0.5: 1.5 \cdot\left(X-x_{2}\right), 0.5 \cdot\left(X-x_{2}\right)$ & $x_{2}$ \\
3-Risk & $X-x_{3}$ & $0.8: 1.25 \cdot x_{3}, 0 \cdot x_{3}$ & $0.8: 1.25 \cdot\left(X-x_{3}\right), 0 \cdot\left(X-x_{3}\right)$ & $x_{3}$ \\
4-Risk & $X-x_{4}$ & $0.5: 2 \cdot x_{4}, 0 \cdot x_{4}$ & $0.5: 2 \cdot\left(X-x_{4}\right), 0 \cdot\left(X-x_{4}\right)$ & $x_{4}$ \\
5-Risk & $X-x_{5}$ & $0.2: 5 \cdot x_{5}, 0 \cdot x_{5}$ & $0.2: 5 \cdot\left(X-x_{5}\right), 0 \cdot\left(X-x_{5}\right)$ & $x_{5}$ \\
\hline
\end{tabular}

B's earnings in RISK-B are characterized by $p: k \cdot x_{n}, \bar{k} \cdot x_{n}$ and G's earnings in RISK-G by $p: k \cdot\left(X-x_{n}\right), \bar{k} \cdot\left(X-x_{n}\right)$

easy to achieve, which allows us to focus on situations where $\mathrm{G}$ and B are equally productive and only differ in their risk exposure. ${ }^{6}$

Part 1.b: Allocation problems In this part of the experiment, $G$ is asked to distribute the amount of money in the group account between himself and $\mathrm{B}$, who is not active in this phase. $\mathrm{G}$ makes decisions in several allocation problems and is informed that only one decision will be randomly selected at the end of the experiment to be relevant for payment.

Table 1 shows the characteristics of each allocation problem in the two experiments. We indicate with $X-x_{n}$ the share kept by $\mathrm{G}$ and with $x_{n}$ the share given to $\mathrm{B}$, in allocation problem $n$. Allocation problem 1-Certainty represents a standard risk-free dictator game, where G's and B's final earnings are equal to the allocation made by $\mathrm{G}$. In the other four allocation problems risk is introduced. We also implemented two allocation problems characterized by ambiguity, in the sense that the outcomes' probabilities are unknown to the subjects. Their characteristics and results are discussed in Section 4.2.

In experiment RISK-B, G's final earnings are equal to the share of $X$ that $\mathrm{G}$ keeps for himself, while the final earnings of B depend on which of two possible states of the world is realized. In the table each risky situation is characterized by $p, k$, and $\bar{k}$, with $k>1$ and $0 \leq \bar{k}<1$. With known probability $p$ the good state is realized and B's earnings are $k$ times the share allocated to her, while with known probability $1-p$ the bad state is realized and B's earnings are a fraction $\bar{k}$ of her allocated share. Conversely, in RISK-G, G's final earnings are risky, while B's earnings are certain and equal to the share chosen by $\mathrm{G}$.

In both experiments and in every allocation problem, the expected value of a given allocation is equal to the allocation itself. This property ensures that givers' behavior cannot be explained by the desire to achieve greater material efficiency in

\footnotetext{
${ }^{6}$ Investigating situations where subjects differ in both risk exposure and productivity could be an interesting avenue for future research. For interesting studies on fairness concerns and productivity differences in situations without risk, see Cherry et al. (2002) and Cappelen et al. (2007).
} 
expectation. To illustrate, consider distribution problem 4-Risk. In experiment RISK$\mathrm{B}$, with probability $p=0.5$, B's earnings are either $2 * x_{4}$ or zero, and in expectation thus equal to $x_{4}$ and G's earnings are equal to $X-x_{4}$ for sure. Conversely, in experiment RISK-G the earnings of $\mathrm{B}$ are certain and equal to $x_{4}$, while $\mathrm{G}$ earns $X-x_{4}$ in expectations $\left(0.5 * 2 *\left(X-x_{4}\right)+0.5 * 0\right)$.

Importantly, in both experiments, $\mathrm{G}$ makes allocation decisions before risk is resolved and with complete knowledge of how risk affects final earnings. The allocation problems are ordered from least risky, 1-Certainty, to most risky, 5-Risk. ${ }^{7}$ By varying the riskiness of the allocation problems we can study whether, beyond the mere presence of risk, giving is also affected by how extreme the final distribution of outcomes can be.

In the experiment allocation problems appear on the computer screen one at a time and the order of appearance is randomized at the G-B pair level. Subjects are informed that the resolution of risk and the determination of earnings takes place publicly at the end of the experiment, and that they will witness how the chance devices are operated. In case a risky distribution problem is selected for payment, a stack of cards numbered from 1 to 100 is used to resolve risk. For instance, if B faces a 50 percent chance that her allocation is doubled, then this indeed happens if a card with a number smaller than 51 is drawn.

Part 2: Elicitation of own risk preferences In this part, we implement incentivized individual decision making tasks in order to elicit participants' own risk preferences. Specifically, we elicit participants' certainty equivalents of six two-outcome lotteries and use these to estimate subjects' risk preferences at the individual level. ${ }^{8}$ Table 2 gives an overview of the outcomes and probabilities of these lotteries. For each lottery, subjects make choices between the lottery and 20 equally spaced sure amounts that are decreasing monotonically from the lottery's highest to lowest outcome. Subjects are not allowed to switch back and forth between the sure amount and the lottery, which guarantees a unique switching point. ${ }^{9}$

For each lottery, certainty equivalents are calculated as the arithmetic mean of the smallest sure amount preferred to the lottery and the next higher sure amount on the list. Following influential experimental literature estimating risk preferences (e.g., Holt and Laury 2002; Andersen et al. 2008; Wakker 2008; Dohmen et al. 2011), we assume a CRRA power utility function for money $U(x)=x^{1-r}$, where $0<r<1$ indicates risk averse, $r=0$ risk neutral and $r<0$ risk seeking preferences. We

\footnotetext{
${ }^{7}$ An allocation problem $n+1$ is defined as being riskier than problem $n$ if for any constant relative risk aversion (CRRA) or constant absolute risk aversion (CARA) utility function for money, the expected utility of a given risky allocation in $n$ is larger than the expected utility of the same allocation in $n+1$.

${ }^{8}$ Subjects engaged also in six ambiguous lotteries, which are not used in estimating risk preferences (see Section 4.2).

${ }^{9} \mathrm{~A}$ screen shot showing how lotteries are presented to subjects can be found in Section $\mathrm{C}$ of the Electronic Supplementary Material (ESM).
} 
Table 2 Lotteries to elicit risk preferences

\begin{tabular}{llll}
\hline Lottery & $p_{1}$ & $x_{1}$ & $x_{2}$ \\
\hline 1 & 0.20 & 40 & 0 \\
2 & 0.50 & 16 & 0 \\
3 & 0.80 & 10 & 0 \\
4 & 0.50 & 12 & 4 \\
5 & 0.25 & 16 & 4 \\
6 & 0.33 & 12 & 0 \\
\hline
\end{tabular}

$p_{1}$ is the probability of winning $€ x_{1}$

estimate the risk preference parameter $r$ at the individual level by minimizing the sum of squared distances (Wakker 2008). That is,

$$
\min _{r} \sum_{i=1}^{6}\left(l_{i}(r)-c e_{i}\right)^{2},
$$

where $l_{i}(r)$ indicates the theoretically predicted certainty equivalent for lottery $i$ given $r$ and $c e_{i}$ is the elicited certainty equivalent of lottery $i$. To correct for heteroscedasticity lotteries are normalized to uniform length. At the end of the experiment one decision is randomly selected to be relevant for payment and earnings are added to those of the first part.

Part 3: Elicitation of beliefs about others' risk preferences In order to elicit participants' beliefs about others' risk preferences, we ask them to estimate the choices made by the other group member in four of the six risky lotteries of Part $2 .{ }^{10}$ Belief elicitation is incentivized using the interval scoring rule. ${ }^{11}$ That is, participants are asked to estimate the interval that contains the switching point of the other person, also allowing for indicating a unique switching point. If the true switching point of the other person lies inside the indicated interval, the guessing participant earns an amount that is inversely proportional to the length of the indicated interval. If the true switching point lies strictly outside the indicated interval, the guessing participant earns nothing.

We use the midpoints of the elicited intervals to calculate believed certainty equivalents. These are then used to estimate, at the individual level, a measure $\bar{r}$ of beliefs about others' risk preferences, using the same estimation method as described above for estimating own risk preferences.

In this part participants could earn a maximum of $€ 1$ per lottery. After the task is finished subjects fill in a post-experiment questionnaire asking questions about their

\footnotetext{
${ }^{10}$ Participants also estimated choices of the other group member in two ambiguous lotteries. These are not used for the estimation of believed risk preferences of others (see Section 4.2).

${ }^{11}$ The interval scoring rule is less time consuming and cognitively less demanding for subjects than, for example, the quadratic scoring rule. Further, Schlag and der Weele (2015) show that it allows inferences that are valid under any degree of subjects' risk aversion.
} 
age, gender, field of study etc. Thereafter their total earnings are determined and they are paid out confidentially in cash.

In total 298 students from Maastricht University participated in the computerized experiments which were conducted at the Behavioral and Experimental Economics lab (BEElab) of Maastricht University School of Business and Economics, using the z-Tree software (Fischbacher 2007). Participants were randomly assigned to either experiment RISK-B or RISK-G. Eighty percent of the participants were enrolled in the School of Business and Economics and the remaining 20 percent followed other studies, such as law, medicine and arts. Forty-eight percent of the participants were male and the average age was 24 years. The experiment lasted approximately 75 minutes and the average earnings per subject were $€ 22$.

\section{Results}

In the real effort task, most subjects were equally and maximally productive, as intended. Specifically, both G and B achieved the maximum of $€ 8$ in 66 of 73 pairs in RISK-B and in 71 of 76 pairs in RISK-G. As our focus is the analysis of the effects of risk and risk preferences on giving, in the following we exclude those pairs where at least one person did not earn the maximum of $€ 8$. Consequently, in the analyzed pairs the joint account always contains $€ 16$. Below, we first present the results of experiment RISK-B followed by the results of experiment RISK-G. For both experiments, we begin by providing some descriptive statistics on all allocation problems. Thereafter, we provide regression analyzes on the effect of individual risk preferences and varying riskiness.

Experiment RISK-B Table 3 provides summary statistics on giving in RISK-B. ${ }^{12}$ We note first that allocations in problem 1-Certainty are in keeping with what is commonly observed in standard dictator games (see Camerer 2003; Engel 2011). Givers transfer on average $€ 3.70$, that is $23 \%$ of the joint account, to the beneficiary, a substantial share of $23 \%$ of givers choose the equal split of $€ 8,32 \%$ allocate nothing to $\mathrm{B}$, and only very few (3\%) give more than the equal split.

In comparing giving in the different allocation problems, Table 3 shows that on average giving first slightly increases with increasing risk. However, starting with 3 Risk giving decreases to reach a minimum in the most risky problem 5-Risk. The figures in the third column of the table show that the number of givers that choose to split the joint account equally monotonically decreases with the riskiness of the problem. The frequency of the selfish choice to give nothing is highest in 1-Certainty but does not differ across risky allocation problems. Finally, 'hyperfair' choices of giving more than the equal split are generally infrequent but appear more often in the risky problems than in 1-Certainty.

To test if risk preferences are predictive for giving we first estimate the risk aversion parameter $r$, as described in Part 2 of Section 2. Consistent with previous results

\footnotetext{
${ }^{12}$ Section A.1 of the ESM provides histograms of the distributions of giving for all allocation problems.
} 
Table 3 Summary statistics of giving in RISK-B

\begin{tabular}{llllll}
\hline Problem & Mean $\left(x_{n}\right)$ & Std.dev. $\left(x_{n}\right)$ & Equal split & No giving & More than equal \\
\hline 1-Certainty & 3.70 & 3.69 & $23 \%$ & $32 \%$ & $3 \%$ \\
2-Risk & 4.12 & 3.63 & $20 \%$ & $26 \%$ & $5 \%$ \\
3-Risk & 4.25 & 3.77 & $14 \%$ & $26 \%$ & $12 \%$ \\
4-Risk & 3.69 & 3.45 & $11 \%$ & $26 \%$ & $5 \%$ \\
5-Risk & 3.00 & 3.28 & $6 \%$ & $27 \%$ & $8 \%$ \\
\hline
\end{tabular}

$N=66$; 'Mean' in $€$; 'Equal split', 'No giving', and 'More than equal' are frequencies in percent

(e.g., Holt and Laury 2002), we find that givers are on average moderately averse to risk (mean $r=0.27$, std.dev. $(r)=0.30$ ). We then use these individual level estimates as an explanatory variable in regression analyses with the various measures of giving presented in Table 3 as dependent variables.

Table 4 shows the results. Specifications (1)-(2) report OLS regressions with $€$ allocations to the beneficiary as the dependent variable. Specifications (3)-(8) report Probit regressions where the dependent variable takes on the value 1 if, respectively, an equal split is offered (Equal split), nothing is given to the beneficiary (Selfish), and more than the equal split is given (Hyperfair). In all Probit specifications the dependent variable takes on the value 0 otherwise. In all regressions standard errors are adjusted for clustering on the individual giver.

Specification (1) shows that giving is positively and significantly associated with risk aversion. That is, the more risk averse givers are, the more money they allocate to beneficiaries. An increase in risk aversion of 0.1 points increases giving by approximately 30 euro cents. In specification (2), the riskiness of the allocation problem is added as a trend variable taking on the value 1 for 1-Certainty, 2 for 2-Risk and so on. The regression result shows that the effect of risk preferences on allocations is robust to controlling for the riskiness of the allocation problem. ${ }^{13}$ In addition, riskiness has an independent effect as increasing riskiness significantly decreases allocations to the beneficiary. Thus, holding risk preferences constant, on average, givers become less generous the larger the outcome risk of beneficiaries.

Specifications (3)-(4) show no effect of risk preferences on the likelihood of equal splits but indicate that this likelihood decreases with the riskiness of the allocation problem. In contrast, specifications (5)-(6) show that givers who are less risk averse are more likely to make the selfish choice of keeping everything. This is consistent with the above reported result that giving increases with givers' risk aversion. The risk beneficiaries face appears to be unrelated to selfish choices. Finally, the likelihood of allocations larger than the equal split is neither related to risk preferences nor to the riskiness of the allocation problem as can be seen from specifications (7)-(8).

\footnotetext{
${ }^{13}$ Below we conduct additional regressions where we replace the trend variable with dummy variables for each allocation problem. The results regarding the effect of risk preferences are also robust to this change in the regression specification.
} 
Table 4 Regressions RISK-B

\begin{tabular}{|c|c|c|c|c|c|c|c|c|}
\hline & (1) & (2) & (3) & (4) & (5) & (6) & (7) & (8) \\
\hline & Allocation & Allocation & Equal split & Equal split & Selfish & Selfish & Hyperfair & Hyperfair \\
\hline Risk aversion & $\begin{array}{l}2.853 * * \\
(1.1756)\end{array}$ & $\begin{array}{l}2.853 * * \\
(1.1774)\end{array}$ & $\begin{array}{l}0.176 \\
(0.1111)\end{array}$ & $\begin{array}{l}0.175 \\
(0.1121)\end{array}$ & $\begin{array}{l}-0.352 * * \\
(0.1550)\end{array}$ & $\begin{array}{l}-0.352 * * \\
(0.1551)\end{array}$ & $\begin{array}{l}0.103 \\
(0.0685)\end{array}$ & $\begin{array}{l}0.102 \\
(0.0686)\end{array}$ \\
\hline Riskiness & & $\begin{array}{l}-0.183^{* * *} \\
(0.0678)\end{array}$ & & $\begin{array}{l}-0.042^{* * *} \\
(0.0108)\end{array}$ & & $\begin{array}{l}-0.009 \\
(0.0081)\end{array}$ & & $\begin{array}{l}0.008 \\
(0.0053)\end{array}$ \\
\hline Constant & $\begin{array}{l}2.977 * * * \\
(0.4536)\end{array}$ & $\begin{array}{l}3.525 * * * \\
(0.5459)\end{array}$ & & & & & & \\
\hline Observations & 330 & 330 & 330 & 330 & 330 & 330 & 330 & 330 \\
\hline Adjusted $R^{2}$ & 0.058 & 0.064 & & & & & & \\
\hline Pseudo $R^{2}$ & & & 0.029 & 0.066 & 0.048 & 0.048 & 0.037 & 0.042 \\
\hline
\end{tabular}

$* p<0.10, * * p<0.05$, *** $p<0.01$; standard errors adjusted for 66 clusters on givers level in parentheses; specifications (1) and (2) report OLS regression results, specifications (3)-(8) report Probit marginal effects

In experiment RISK-B the risk is on the beneficiaries' side and it is therefore conceivable that givers' allocation decisions are also affected by their beliefs about others' risk preferences. In Part 3 of the experiment we have elicited these beliefs $\bar{r}$ and find that they are on average very similar to givers' own risk preferences (mean $\bar{r}=0.28$, std.dev. $(\bar{r})=0.33$ ). Moreover, the two measures, $r$ and $\bar{r}$, are significantly positively correlated (Pearson correlation $=0.54, p<0.01$ ). The observed correlation is consistent with the so-called 'false consensus effect', that is, the tendency of people to overestimate the extent to which their beliefs, preferences and values are similar to those of others (see Mullen et al. 1985 for an extensive metastudy on the false consensus effect and Engelmann and Strobel (2000) for a critical examination).

When regressing allocations to $\mathrm{B}$ on the riskiness of the allocation problem and on believed risk preferences of others instead of own risk preferences (cf. Table 4, specification (2)) we find that believed risk preferences are marginally significantly and positively correlated with giving (see Table A.1 in Section A.2 of the ESM). The strong correlation between $r$ and $\bar{r}$ makes it difficult to determine whether own risk preferences or beliefs about others' risk preferences or both are predictive for giving. However, when adding own risk preferences as an explanatory variable to the regression these are marginally significant, whereas beliefs about others' risk preferences cease to be significant. This suggests that it is own risk preferences rather than beliefs about others' risk preferences that affects givers' generosity.

We close the discussion of results in RISK-B by taking a more detailed look at how the riskiness of the allocation problem, individuals' risk aversion, and the interaction of both affect giving. Specifically, we run OLS regressions with allocations of givers as the dependent variable and dummy variables indicating the riskiness of the allocation problem as well as givers' risk aversion as independent variables. To examine whether the effect of risk aversion changes with the riskiness of the allocation 
problem we add interactions between the riskiness dummies and the risk aversion variable. Table 5 reports the results of these regressions as specification (1) and (2), respectively.

We first note that in both specifications the coefficient of givers' risk aversion is significant. Thus, the effect of givers' risk preferences on allocations reported in Table 4 is robust to these specifications. Specification (1) shows that allocations first slightly increase and then decrease along the riskiness dimension. $F$-tests indicate that the riskiness dummies are jointly significantly different and that this difference is driven by 5-Risk, where allocations are significantly smaller than in the other allocation problems (pair-wise tests, $p \leq 0.0046$ ). All other pair-wise comparisons are

Table 5 Regressions for RISK-B riskiness dummies, risk aversion and interaction effects

\begin{tabular}{|c|c|c|}
\hline & $\begin{array}{l}\text { No interactions } \\
\text { (1) }\end{array}$ & $\begin{array}{l}\text { With interactions } \\
\text { (2) }\end{array}$ \\
\hline Constant (1-Certainty) & $\begin{array}{l}2.923 * * * \\
(0.4915)\end{array}$ & $\begin{array}{l}2.776 * * * \\
(0.5279)\end{array}$ \\
\hline 2-Risk & $\begin{array}{l}0.424 \\
(0.2701)\end{array}$ & $\begin{array}{l}0.719 \\
(0.4416)\end{array}$ \\
\hline 3-Risk & $\begin{array}{l}0.552 * \\
(0.3048)\end{array}$ & $\begin{array}{l}0.723 \\
(0.4616)\end{array}$ \\
\hline 4-Risk & $\begin{array}{l}-0.008 \\
(0.2825)\end{array}$ & $\begin{array}{l}0.170 \\
(0.3894)\end{array}$ \\
\hline 5-Risk & $\begin{array}{l}-0.697 * * \\
(0.2894)\end{array}$ & $\begin{array}{l}-0.607 * \\
(0.3568)\end{array}$ \\
\hline Risk aversion & $\begin{array}{l}2.853 * * \\
(1.1828)\end{array}$ & $\begin{array}{l}3.394 * * \\
(0.7323)\end{array}$ \\
\hline 2-Risk $*$ Risk aversion & & $\begin{array}{l}-1.088 \\
(1.0400)\end{array}$ \\
\hline 3-Risk*Risk aversion & & $\begin{array}{l}-0.633 \\
(1.0221)\end{array}$ \\
\hline 4-Risk $*$ Risk aversion & & $\begin{array}{l}-0.654 \\
(1.0149)\end{array}$ \\
\hline 5-Risk*Risk aversion & & $\begin{array}{l}-0.333 \\
(1.1099)\end{array}$ \\
\hline Observations & 330 & 330 \\
\hline Adjusted $R^{2}$ & 0.059 & 0.048 \\
\hline \multicolumn{3}{|c|}{$F$-tests of joint significance ( $P$-value $)$} \\
\hline Riskiness dummies & 0.0031 & 0.0033 \\
\hline Interactions & & 0.8298 \\
\hline
\end{tabular}

$* p<0.10, * * p<0.05$, *** $p<0.01$; OLS regressions; in parentheses standard errors adjusted for 66 on givers level 
Table 6 Summary statistics of giving in RISK-G

\begin{tabular}{llllll}
\hline Problem & Mean $\left(x_{n}\right)$ & Std.dev. $\left(x_{n}\right)$ & Equal split & No giving & More than equal \\
\hline 1-Certainty & 4.17 & 4.15 & $30 \%$ & $34 \%$ & $6 \%$ \\
2-Risk & 3.89 & 3.54 & $15 \%$ & $31 \%$ & $7 \%$ \\
3-Risk & 3.96 & 3.59 & $14 \%$ & $27 \%$ & $7 \%$ \\
4-Risk & 4.44 & 3.84 & $17 \%$ & $28 \%$ & $10 \%$ \\
5-Risk & 3.99 & 4.06 & $15 \%$ & $37 \%$ & $11 \%$ \\
\hline
\end{tabular}

$N=71$; 'Mean' in $€$; 'Equal split', 'No giving', and 'More than equal' are frequencies in percent

statistically not significant ( $p \geq 0.1029$ ). Turning to specification (2) we see that the results across the riskiness dimension remain qualitatively the same. Pair-wise comparisons again show that only in 5-Risk allocations are significantly smaller than in all other allocation problems involving risk $(p \leq 0.0030)$. The insignificance of the interaction variables $(p \geq 0.300)$ indicates that the effect of risk aversion is independent of the riskiness of the allocation problem. At first sight it may appear counter-intuitive that the effect of risk aversion is the same in 1-Certainty and the allocation problems with risk. We come back to this in Section 4.1 when we relate the empirical results to a model of other-regarding preferences under risk.

Experiment RISK-G In this section we analyze giving decisions in RISK-G, that is, in allocation problems where givers themselves are exposed to outcome risk. We proceed in the same way as for experiment RISK-B and start with some descriptive statistics shown in Table $6 .{ }^{14}$

Allocations in 1-Certainty are similar to those observed in the same problem in experiment RISK-B and in standard dictator games. ${ }^{15}$ Givers allocate on average $€ 4.17$ to the beneficiary, that is $26 \%$ of the joint account. Thirty percent of givers choose the equal split, $34 \%$ give nothing to $\mathrm{B}$, and $6 \%$ give more than the equal split of $€ 8$.

The average allocations in Table 6 do not exhibit a clear pattern along the riskiness dimension, suggesting that on average allocations are not related to the riskiness of G's earnings. Interestingly, the frequency of equal splits drops by $50 \%$ when moving from 1-Certainty to 2-Risk but stays more or less constant across the different allocation problems with risk. In contrast, the frequency of selfish choices is largely unaffected by the risk borne by G. On the other hand, hyperfair allocations of more than the equal split appear to be slightly increasing with the riskiness of the allocation problem.

Similar to experiment RISK-B, also in RISK-G givers are moderately risk averse (mean $r=0.14$, std.dev. $(r)=0.37) .{ }^{16}$ To test for the effect of risk preferences we

\footnotetext{
${ }^{14}$ Section A.1 of the ESM provides histograms of the distributions of giving for all allocation problems.

${ }^{15}$ There is no statistically significant difference between RISK-G and RISK-B when comparing giving in 1-Certainty (Mann-Whitney rank-sum test, $p=0.6243,2$-sided).

${ }^{16}$ Compared to RISK-B, givers in RISK-G are marginally significantly less risk averse (Mann-Whitney rank-sum test, $p=0.0508$, two-sided.)
} 
conduct regression analysis with specifications equivalent to those for experiment RISK-B. Table 7 reports the results. Specifications (1)-(2) show that allocations to B are significantly negatively related with risk aversion of the giver. That is, the more risk averse givers are, the less they give to beneficiaries. Put differently, more risk averse givers appear to compensate themselves more for their exposure to risk. This resonates well with the finding in RISK-B where we observe that more risk averse givers compensate beneficiaries for their risk exposure more than less risk averse givers do. In contrast to RISK-B, the riskiness of the allocation problem is not a significant determinant of giving.

The Probit estimates in specifications (3)-(4) show that G's risk aversion is unrelated to the likelihood of splitting resources equally and that it is significantly decreasing with the riskiness of the allocation problem. Thus, as in RISK-B, also in RISK-G givers are less inclined to share resources equally when earnings become more risky. Interestingly, selfish choices of giving nothing are related neither to givers' risk aversion nor to the riskiness of the allocation problem (see specifications (5)-(6)). In contrast, specifications (7)-(8) show that the likelihood of making hyperfair offers of more than the equal split are significantly negatively related to givers' risk aversion and significantly positively related to the riskiness of the allocation problem.

Similarly to RISK-B, we find that beliefs about the risk preferences of others are on average similar to givers' own risk preferences (mean $\bar{r}=0.14$, std.dev. $(\bar{r})=$ 0.42 ) and that the two measures are positively correlated (Pearson correlation $=0.59$, $p<0.01$ ). We have also run regressions with allocations as the dependent variable and beliefs about risk preferences of others as an (additional) explanatory variable. In these regressions beliefs are never significant, irrespective of whether they are included next to only riskiness or next to riskiness and own risk aversion. The latter remain significantly negative when including believed risk preferences (see Table A.1

Table 7 Regressions RisK-G

\begin{tabular}{|c|c|c|c|c|c|c|c|c|}
\hline & (1) & (2) & (3) & (4) & (5) & (6) & (7) & (8) \\
\hline & Allocation & Allocation & Equal split & Equal split & Selfish & Selfish & Hyperfair & Hyperfair \\
\hline Risk aversion & $\begin{array}{l}-1.672 * * \\
(0.7280)\end{array}$ & $\begin{array}{l}-1.672 * * \\
(0.7291)\end{array}$ & $\begin{array}{l}-0.011 \\
(0.0740)\end{array}$ & $\begin{array}{l}-0.013 \\
(0.0733)\end{array}$ & $\begin{array}{l}-0.021 \\
(0.0923)\end{array}$ & $\begin{array}{l}-0.021 \\
(0.0922)\end{array}$ & $\begin{array}{l}-0.117 * * \\
(0.0454)\end{array}$ & $\begin{array}{l}-0.118^{* * * *} \\
(0.0455)\end{array}$ \\
\hline Riskiness & & $\begin{array}{l}0.025 \\
(0.1083)\end{array}$ & & $\begin{array}{l}-0.027^{* *} \\
(0.0121)\end{array}$ & & $\begin{array}{l}0.004 \\
(0.0123)\end{array}$ & & $\begin{array}{l}0.016 * * \\
(0.0076)\end{array}$ \\
\hline Constant & $\begin{array}{l}4.367 * * * \\
(0.4043)\end{array}$ & $\begin{array}{l}4.293 * * * \\
(0.5177)\end{array}$ & & & & & & \\
\hline Observations & 345 & 345 & 345 & 345 & 345 & 345 & 345 & 345 \\
\hline Adjusted $R^{2}$ & 0.023 & 0.021 & & & & & & \\
\hline Pseudo $R^{2}$ & & & 0.000 & 0.011 & 0.000 & 0.000 & 0.063 & 0.075 \\
\hline
\end{tabular}

$* p<0.10, * * p<0.05$, *** $p<0.01$; standard errors adjusted for 69 clusters on givers level in parentheses; specifications (1) and (2) report OLS regression results, specifications (3)-(8) report Probit marginal effects; two givers are excluded from the analysis because their estimated risk aversion is infinite 
in Section A.2 of the ESM). Hence, in RISK-G own risk preferences are robust determinants of givers' generosity under risk.

As for RISK-B we close the discussion of results in RISK-G by taking a more detailed look at how the riskiness of the decision situation, individuals' risk aversion, and the interaction of both affect giving. Table 8 reports the regression results. In both regressions the coefficient of givers' risk aversion is negative and significant, showing that the effect of givers' risk preferences on allocations reported in Table 7 is robust to these specifications. All other variables however are statistically not significant. Thus, in RISK-G there is neither a direct effect of riskiness on giving nor does the effect of

Table 8 Regressions for RISK-G riskiness dummies, risk aversion and interaction effects

\begin{tabular}{|c|c|c|}
\hline & $\begin{array}{l}\text { No interactions } \\
\text { (1) }\end{array}$ & $\begin{array}{l}\text { With interactions } \\
\text { (2) }\end{array}$ \\
\hline Constant (1-Certainty) & $\begin{array}{l}4.416^{* * * *} \\
(0.5165)\end{array}$ & $\begin{array}{l}4.654^{* * * *} \\
(0.5598)\end{array}$ \\
\hline 2-Risk & $\begin{array}{l}-0.290 \\
(0.4308)\end{array}$ & $\begin{array}{l}-0.714 \\
(0.5989)\end{array}$ \\
\hline 3-Risk & $\begin{array}{l}-0.116 \\
(0.4540)\end{array}$ & $\begin{array}{l}-0.490 \\
(0.5932)\end{array}$ \\
\hline 4-Risk & $\begin{array}{l}0.362 \\
(0.5149)\end{array}$ & $\begin{array}{l}0.001 \\
(0.5291)\end{array}$ \\
\hline 5-Risk & $\begin{array}{l}-0.203 \\
(0.4662)\end{array}$ & $\begin{array}{l}-0.234 \\
(0.4732)\end{array}$ \\
\hline Risk aversion & $\begin{array}{l}-1.671 * * \\
(0.7323)\end{array}$ & $\begin{array}{l}-3.315^{* *} \\
(1.4570)\end{array}$ \\
\hline 2-Risk*Risk aversion & & $\begin{array}{l}2.927 \\
(2.2434)\end{array}$ \\
\hline 3-Risk*Risk aversion & & $\begin{array}{l}2.583 \\
(1.9808)\end{array}$ \\
\hline 4-Risk*Risk aversion & & $\begin{array}{l}2.491 \\
(1.1205)\end{array}$ \\
\hline 5-Risk*Risk aversion & & $\begin{array}{l}0.214 \\
(1.1686)\end{array}$ \\
\hline Observations & 345 & 345 \\
\hline Adjusted $R^{2}$ & 0.015 & 0.019 \\
\hline \multicolumn{3}{|c|}{$F$-tests of joint significance ( $P$-value $)$} \\
\hline Riskiness dummies & 0.6029 & 0.7043 \\
\hline Interactions & & 0.1213 \\
\hline
\end{tabular}

$* p<0.10, * * p<0.05, * * * p<0.01$; OLS regressions; in parentheses standard errors adjusted for 69 clusters on givers level; two givers are excluded from the analysis because their estimated risk aversion is infinite 
risk aversion interact with the riskiness of the allocation problem. We discuss this outcome in relation to a model of social preferences under risk in Section 4.1 below.

\section{Discussion}

In this section we first discuss our empirical results in relation to a simple model of other-regarding preferences that allows for ex-ante and ex-post fairness concerns as well as for risk aversion. Thereafter, we briefly report the results of allocation problems under ambiguity.

\subsection{Ex-ante and ex-post fairness, riskiness, and risk aversion}

In the literature a few theoretical models of social preferences where risk is explicitly taken into account have been proposed (see, e.g., Trautmann 2009; Krawczyk 2011; Saito 2013). ${ }^{17}$ For instance, the model put forward by Saito (2013) allows for an exante and an ex-post view of fairness in the presence of outcome risk. However, these models assume (piece-wise) linearity in own and others' earnings and are therefore silent about the potential effect of risk aversion found in our experiments. To circumvent this shortcoming we propose here a simple generalization of the existing models and discuss the extent to which such a model's prediction is consistent with our data. Specifically, we combine the expected inequality-aversion model of Saito (2013) with Neilson's 2006 non-linear generalization of the Fehr and Schmidt (1999) model of other-regarding preferences. ${ }^{18}$ We use this model to derive qualitative predictions for each allocation problem in both of our experiments.

Before moving on we want to emphasize that it is not our aim to provide a test of such a model. Our experiments were not designed with this objective in mind and the following discussion should be viewed as such. Our discussion will show that many questions remain open and we hope that it inspires further experimental and theoretical work on other-regarding preferences in the face of risk.

Building on Saito (2013), we assume that in choosing an allocation $\mathbf{x}$ the decision maker, the giver in our experiment, may care both about inequality in ex-ante expected payoffs and in ex-post realized outcomes, as described by

$$
V(\mathbf{x})=\delta U\left(E_{p}(\mathbf{x})\right)+(1-\delta) E_{p}(U(\mathbf{x})) .
$$

The term $U\left(E_{p}(\mathbf{x})\right)$ captures the utility of expected payoffs and is referred to as ex-ante utility, whereas the term $E_{p}(U(\mathbf{x}))$ captures the expected utility of ex-post payoffs and is referred to as ex-post utility. The parameter $\delta \in[0,1]$ measures the relative importance that the giver attributes to ex-ante utility. The function $U(\mathbf{x})=$ $u_{1}\left(X-x_{n}\right)-\alpha u_{2}\left(\max \left\{x_{n}-\left(X-x_{n}\right), 0\right\}\right)-\beta u_{2}\left(\max \left\{\left(X-x_{n}\right)-x_{n}, 0\right\}\right)$ reflects a non-linear generalization of the inequity aversion model of Fehr and Schmidt (1999),

\footnotetext{
${ }^{17}$ See also Fudenberg and Levine (2012) for a discussion on the problems of extending social preferences models to lotteries.

${ }^{18}$ Neilson (2006) shows that a preference ordering satisfying completeness, transitivity, continuity and a separability axiom called 'self-referent separability' can be uniquely represented by a function $U(x)=$ $u_{0}\left(x_{0}\right)+\sum_{i=1}^{n} u_{i}\left(x_{i}-x_{0}\right)$, where utility functions $u_{0}, \ldots, u_{n}$ are unique up to a joint increasing affine transformation.
} 
with $u_{1}$ and $u_{2}$ being concave and strictly increasing in its argument. The term $X-x_{n}$ is the monetary payoff of the giver and $x_{n}$ is the monetary payoff of the beneficiary in our experiments. The parameters $\alpha \geq 0$ and $\beta \in[0,1$ [ with $\beta \leq \alpha$ capture aversion to respectively disadvantageous and advantageous inequality.

In the following we first present the qualitative predictions in terms of allocations across the riskiness of the allocation problems and compare them to the observed behavior in our experiment. Thereafter we discuss potential effects of risk aversion and how these compare to our data. All formal proofs can be found in Section B of the ESM.

Table 9 summarizes the allocation predictions of the model across all decision problems and for pure ex-ante utility $(\delta=1)$ (Panel a), which is equivalent to 1-Certainty, and pure ex-post utility $(\delta=0)$ for both RISK-B and RISK-G (Panel b and Panel c, respectively). From Panel a we see that, depending on the strength of social preferences, givers should allocate to beneficiaries between zero (if $\beta<\beta_{1}$ ) and anything up to 8 (if $\beta \geq \beta_{1}$ ). Comparing these with the average actual allocations in 1-Certainty reported in Table 3 for RISK-B and Table 6 for RISK-G, we see that actual allocations indeed fall mostly into this range (only very few givers allocate more than half of the endowment to the beneficiary). Note that pure ex-ante utility implies no change of giving across allocation problems. We have seen, however, that (at least in RISK-B) giving is affected by the riskiness of the allocation problem and can thus not be explained on the basis of ex-ante utility alone. We therefore conclude that overall allocations are consistent with givers having, on average, sufficiently strong other-regarding preferences and a mixture of ex-ante and ex-post concerns. This observation is in line with earlier results (e.g., Krawczyk 2010; Brock et al. 2013).

We next focus on ex-post utility in RISK-B. From Panel b in Table 9 we note that the other-regarding preferences threshold for giving a positive amount, $\beta_{1}$, is the same in all allocation problems and that this threshold is independent of the parameters $p, k$, and $\bar{k}$, which determine the riskiness of the allocation problem. It thus follows that the frequency of decisions that allocate nothing to the beneficiary should not vary across the allocation problems. This is indeed what we find in our data (see Table 3 column "No giving" and Table 4 specification (6)). Further predictions are less straightforward as the other threshold, $\beta_{2}$, is not independent of and does not vary monotonically with the riskiness of the allocation problem. Nevertheless, it appears reasonable to expect that positive allocations tend to decrease with the riskiness of the allocation problem for the following reasons. First, for advantageous inequality aversion that is not too strong $\left(\beta<\beta_{2}\right)$ the predicted positive allocations tend to decrease with increasing riskiness, and second, in the literature there is little evidence for high $\beta$ values (see, e.g., Fehr and Schmidt 1999) that could countervail this effect. We indeed find evidence for decreased giving with increasing riskiness (see Table 3 columns "Mean" and "Equal split" and Table 4 specification (2)). That this effect is mainly driven by 5-Risk (see Table 5) is also consistent with the predictions.

The threshold $\beta_{1}$ for giving a positive amount is independent of the riskiness of the allocation problem but does depend on the concavity of $u_{1}$ and $u_{2}$ and thus the risk aversion of the giver. It can be shown that for a given concavity of $u_{2}$ as well as for $u_{1}=u_{2}$, an increase in risk aversion in the self-regarding utility component $u_{1}$ 
Table 9 Optimal giving in RISK-B and RISK-G with ex-ante utility $(\delta=1)$ and ex-post utility $(\delta=0)$ in dependence of strength of social preferences

(a) 1-Certainty and ex-ante utility $(\delta=1)$ in both RISK-B and RISK-G

\begin{tabular}{cc|c|c}
\hline \hline & \multicolumn{3}{c}{ strength of social preferences: $\beta \in$} \\
\cline { 2 - 4 } & {$\left[0, \beta_{1}[\right.$} & $\left\{\beta_{1}\right\}$ & ]$\beta_{1}, 1[$ \\
\hline 1-Certainty & 0 & ] $0,8[$ & 8 \\
\hline
\end{tabular}

(b) Ex-post utility $(\delta=0)$ in RISK-B

\begin{tabular}{cc|c|c|c|c}
\hline & \multicolumn{5}{c}{ strength of social preferences: $\beta \in$} \\
\cline { 2 - 6 } & {$\left[0, \beta_{1}[\right.$} & $\left\{\beta_{1}\right\}$ & ]$\beta_{1}, \beta_{2}[$ & $\left\{\beta_{2}\right\}$ & ]$\beta_{2}, 1[$ \\
\hline 2-Risk & 0 & ] $0,6.4[$ & 6.4 & ] $6.4,10.7[$ & 10.7 \\
\hline 3-Risk & 0 & ] $0,7.1[$ & 7.1 & ] $7.1,16[$ \\
\hline 4-Risk & 0 & ] $0,5.3[$ & 5.3 & ] $5.3,16[$ \\
\hline 5-Risk & 0 & ] $0,2.7[$ & 2.7 & ] $2.7,16[$ \\
\hline
\end{tabular}

(c) Ex-post utility $(\delta=0)$ in Risk-G

\begin{tabular}{lc|c|c|c|c}
\hline & \multicolumn{5}{c}{ strength of social preferences: $\beta \in$} \\
\cline { 2 - 6 } & {$\left[0, \beta_{3}[\right.$} & $\left\{\beta_{3}\right\}$ & ]$\beta_{3}, \beta_{4}[$ & $\left\{\beta_{4}\right\}$ & ]$\beta_{4}, 1[$ \\
\hline 2-Risk & 0 & ] $0,5.3[$ & 5.3 & ] $5.3,9.6[$ & 9.6 \\
\hline 3-Risk & 0 & & ] $0,8.9[$ & 8.9 \\
\hline 4-Risk & 0 & ] $0,10.7[$ & 10.7 \\
\hline 5-Risk & 0 & ] $0,13.3[$ & 13.3 \\
\hline
\end{tabular}

Note: Predictions are identical for 1-Certainty and all allocation problems with risk assuming pure ex-ante utility. $\beta_{1}:=\frac{u_{1}^{\prime}\left(16-x_{n}\right)}{2 u_{2}^{\prime}\left(16-2 x_{n}\right)}$ is independent of the riskiness of the allocation problem. $\quad \beta_{2}:=\frac{u_{1}^{\prime}\left(16-x_{n}\right)+\alpha p(k+1) u_{2}^{\prime}\left((k+1) x_{n}-16\right)}{(1-p)(\bar{k}+1) u_{2}^{\prime}\left(16-(\bar{k}+1) x_{n}\right)}$, $\beta_{3}:=\frac{p k u_{1}^{\prime}\left(16 k-k x_{n}\right)+(1-p) \bar{k} u_{1}^{\prime}\left(16 \bar{k}-\bar{k} x_{n}\right)}{p(k+1) u_{2}^{\prime}\left(16 k-(k+1) x_{n}\right)+(1-p)(\bar{k}+1) u_{2}^{\prime}\left(16 \bar{k}-(\bar{k}+1) x_{n}\right)}$, and $\beta_{4}:=$ $\frac{p k u_{1}^{\prime}\left(16 k-k x_{n}\right)+(1-p) \bar{k} u_{1}^{\prime}\left(16 \bar{k}-\bar{k} x_{n}\right)+(1-p) \alpha(\bar{k}+1) u_{2}^{\prime}\left((\bar{k}+1) x_{n}-16 \bar{k}\right)}{p(k+1) u_{2}^{\prime}\left(16 k-(k+1) x_{n}\right)}$ do depend on the riskiness of the allocation problem. In all panels the optimal giving amounts are rounded values; the exact values can be found in Section B of the ESM. 
leads to a decrease of $\beta_{1} \cdot{ }^{19}$ Thus, the model predicts that allocations may increase with increasing risk aversion of the giver in 1-Certainty and in allocation problems with risk but that there is not necessarily an interaction effect (positive or negative) of riskiness and risk aversion on allocation decisions. This is consistent with the regression results shown in Table 5.

Turning to ex-post utility in RISK-G we see from Panel c in Table 9 that comparative statics predictions across the riskiness of allocation problems are not straightforward. First, the relation between $\beta_{1}$, on the one hand, and $\beta_{3}$ and $\beta_{4}$, on the other hand, is ambiguous making a comparison of 1-Certainty with the other allocation problems impossible. Moreover, both $\beta_{3}$ and $\beta_{4}$ depend non-trivially on the concavity of $u_{1}$ and $u_{2}$ as well as the parameters $p, k$, and $\bar{k}$, which determine the riskiness of the allocation problems. Thus clear predictions are difficult to derive. However, under some assumptions on the shape of the functions $u_{1}$ and $u_{2}$ it can be shown that $\beta_{3}$ is smaller than $\beta_{4}$ and that $\beta_{4}$ is increasing with the riskiness parameter $k$. Together this implies that the fraction of decisions allocating nothing to the beneficiary should weakly increase from 2-Risk to 5-Risk. Our regression result in Table 7 (specification (6)) shows a positive but statistically insignificant correlation of the frequency of giving nothing with the riskiness of the allocation problem. In that sense, the data from the experiment are consistent with the model's prediction.

Panel $\mathrm{c}$ in Table 9 suggests also that increasing riskiness may increase hyperfair giving - that is, allocations larger than the equal split of 8 - because the maximum predicted amounts tend to increase with riskiness. ${ }^{20}$ The regression analysis in Table 7 (specification (8)) reports a significantly positive correlation between hyperfair allocations and riskiness and the results reported in Table 6 (column (More than equal)) suggest that this is driven mainly by 4-Risk and 5-Risk. Both observations are consistent with the predictions. However, this does not necessarily imply that allocations generally increase with risk because the mentioned $\beta$ thresholds are also increasing and the model is generally silent about the distribution of positive allocations.

Turning to individuals' risk aversion we note that the observed negative effect of risk aversion on giving is at odds with the model's predictions. Moreover, the effect of changing risk aversion on the $\beta$ thresholds is generally ambiguous, impeding clear comparative statics predictions.

In summary, we find that the proposed model organizes important aspects of the data surprisingly well for RISK-B but that this is much less the case for RISK-G. Especially, the observed negative effect of risk aversion on giving in all allocation problems in the latter experiment is hard to square with the model's predictions. In a sense, this is not too surprising as the model is a first attempt to incorporate ex-ante and ex-post fairness concerns, other-regarding preferences, and risk aversion in one (simple) model and thus does not consider a number of other potentially important motivations of social behavior under risk. It is clear that further empirical and theoretical investigations are necessary to better understand all aspects of these different

\footnotetext{
${ }^{19}$ In Section B of the ESM this is shown assuming constant relative risk aversion.

${ }^{20}$ The intuition for this result is that increasing riskiness also implies potentially large advantageous inequality ex-post due to increasing high earnings in the good state and limited low earnings in the bad state.
} 
motivations. We mention here just a few that could be especially interesting for future research.

In our analysis we have retained expected utility assumptions. There is however ample evidence that observed behavior under risk often violates such assumptions (Rabin 2000). For instance, people tend to weight probabilities non-linearly and evaluate outcomes with respect to endogenously formed reference points (see Kahneman and Tversky 1979, 1991; Kőszegi and Rabin 2006). Future research could incorporate these important behavioral aspects into models of social decision making under risk and test them empirically.

We find that when beneficiaries are exposed to risk, they are allocated less when the riskiness of their earnings is high. As discussed, this is consistent with givers being not only concerned with ex-ante fairness but also taking ex-post fairness considerations into account. An alternative interpretation is suggested by the observations of Haisley and Weber (2010), who find that generosity decreases in environments where self-serving interpretations of fairness are available for the decision maker (see also Broberg et al. 2007; Dana et al. 2007). Thus, givers may behave less generously when allocations for beneficiaries are riskier by focusing on the beneficiaries' high possible outcome and ignoring the low one. Such a self-centered view may also be consistent with the negative effect of risk aversion on giving in RISK-G, if self-centeredness is correlated with risk preferences and own risk exposure.

Givers may also have a concern for ex-ante material efficiency, which was ruled out by design in our experiments. For instance, risk averse givers may perceive that the aggregate expected utility at the pair level increases when money is allocated away from the side bearing the risk. If selfish motives are traded off against these type of efficiency concerns, we may expect that there is on average no effect of riskiness on allocations, as observed in our experiment where givers had to bear the risk. To test this hypothesis future research could propose a model incorporating social and risk preferences as well as efficiency concerns.

\subsection{Allocation problems characterized by ambiguity}

Our experiments also included two allocation problems characterized by ambiguity, that is, problems in which the probability of either state is unknown to the giver. We implement these problems because outside the experimental laboratory often decisions have to be taken without precise probabilistic information. In order to operationalize ambiguity in the laboratory, we used a stack of 100 cards colored black and red. Participants were free to choose a winning color at the beginning of the experiment, but neither the participants nor the experimenter knew the exact color composition of the stack. Participants were informed that, in case one of these allocation problems turned out to be relevant for payment, at the end of the experiment the winning color would be determined by randomly drawing a card from the stack. 
Table 10 Allocation problems with ambiguity in RISK-B and RISK-G

\begin{tabular}{llllll}
\hline & RISK-B & & RISK-G & \\
\cline { 2 - 3 } \cline { 5 - 6 } Problem & G's earnings & B's earnings & & G's earnings & B's earnings \\
\hline 6-Ambiguity & $X-x_{6}$ & $\tilde{p}: 1.5 \cdot x_{6}, 0.5 \cdot x_{6}$ & $\tilde{p}: 1.5 \cdot\left(X-x_{6}\right), 0.5 \cdot\left(X-x_{6}\right)$ & $x_{6}$ \\
7-Ambiguity & $X-x_{7}$ & $\tilde{p}: 2 \cdot x_{7}, 0 \cdot x_{7}$ & $\tilde{p}: 2 \cdot\left(X-x_{7}\right), 0 \cdot\left(X-x_{7}\right)$ & $x_{7}$ \\
\hline
\end{tabular}

B's earnings in RISK-B are characterized by $\tilde{p}: k \cdot x_{n}, \bar{k} \cdot x_{n}$ and G's earnings in RISK-G by $\tilde{p}: k \cdot\left(X-x_{n}\right), \bar{k} \cdot\left(X-x_{n}\right)$, where $\tilde{p}$ is an unknown probability between 0 and 1

Table 10 displays the allocation problems' characteristics, where the unknown probability is indicated by $\tilde{p}$. Note that problem 6-Ambiguity (7-Ambiguity) is the ambiguous equivalent of problem 2-Risk (4-Risk). We do not have model-based predictions but since individuals are usually ambiguity averse (see, e.g., Ellsberg 1961; Dimmock et al. 2015), we considered that ambiguity may have similar effects as increased risk aversion in allocation problems under risk.

Table 11 shows descriptive statistics on giving in the presence of ambiguity. We find that in RISK-B allocations in 6-Ambiguity are only marginally significantly lower than in 2-Risk (Wilcoxon signed-rank test, $p=0.082$ ), while allocations in 7Ambiguity and 4-Risk are statistically indistinguishable (Wilcoxon signed-rank test, $p=0.693$ ). In RISK-G we find that allocations in the ambiguous problems are not significantly different from the corresponding risky ones (Wilcoxon signed-rank test, $p=0.381$ and $p=0.786$, respectively). These results suggest that in our experiments givers treat allocation problems under ambiguity similarly to equivalent ones under risk.

In what follows we present the analysis of subjects' attitudes to ambiguity, and beliefs about others' attitudes, which confirms this interpretation. In Part 2 of the experiment subjects faced two decision screens where they made 20 choices between a fixed lottery with known outcomes but unknown probabilities (i.e., an ambiguous lottery), and a lottery with the same possible outcomes and a known probability

Table 11 Summary statistics of giving under ambiguity in RISK-B and RISK-G

\begin{tabular}{lllllll}
\hline Experiment & Problem & Mean $\left(x_{n}\right)$ & Std.dev. $\left(x_{n}\right)$ & Equal split & No giving & More than equal \\
\hline \multirow{2}{*}{ Risk-B } & 6-Ambiguity & 3.83 & 3.89 & $12 \%$ & $26 \%$ & $8 \%$ \\
& 7-Ambiguity & 3.82 & 3.48 & $15 \%$ & $24 \%$ & $3 \%$ \\
\multirow{2}{*}{ Risk-G } & 6-Ambiguity & 3.72 & 3.89 & $14 \%$ & $32 \%$ & $10 \%$ \\
& 7-Ambiguity & 4.17 & 3.86 & $20 \%$ & $34 \%$ & $11 \%$ \\
\hline
\end{tabular}

$N=66$ in RISK-B and $N=71$ in RISK-G 
distribution, that varies in steps of $5 \%$ (i.e., 20 risky lotteries). ${ }^{21}$ The switching point from one type of lottery to the other is an indication of a subject's subjective belief about the ambiguous event, and in this sense represents a measure of ambiguity attitude. For instance, switching to the ambiguous lottery when the winning probability of the risky lottery is $40 \%$ reveals stronger ambiguity aversion than switching when the risky probability is $60 \%$. In Part 3, beliefs about the ambiguity attitudes of the other group member are elicited by asking subjects to guess the interval that contains the other's switching point, in the same way as for beliefs about risk attitudes.

We find that in both experiments givers are close to being ambiguity neutral, as they switch to the ambiguous lottery when the risky lottery has a winning probability close to 0.5 ( 0.47 in RISK-B and 0.46 in RISK-G). Moreover givers' ambiguity attitudes and beliefs are significantly correlated (Pearson correlation $\geq 0.49$, $p<0.01)$.

\section{Conclusions}

In this paper we investigated individuals' giving behavior in situations where respectively givers and beneficiaries are exposed to various degrees of risk. We also collected data on individuals' risk preferences and on their beliefs about the risk preferences of others, both in isolation from social preferences. We find that givers' risk preferences are an important determinant of generosity. A more risk averse giver allocates more to the beneficiary when the risk is on the beneficiary's side and allocates less when the risk is on the giver's side. Beliefs about the risk preferences of others play basically no role. Thus, givers appear to compensate the side that has to bear the risk, taking their own risk preferences into account.

Existing models of other-regarding preferences do not take into account individual risk preferences of those involved. Our evidence shows however that risk preferences are important in social decision situations and that the predictive power of such models would likely be improved when explicitly taking into account attitudes toward risk. We propose a simple model allowing for other-regarding preferences, ex-ante and ex-post views of fairness, and risk preferences. We find that behavior is surprisingly consistent with the model's predictions when the risk is on the beneficiary's side. However, when risk is on the giver's side consistency is worse and especially the effect of risk aversion is at odds with the model's prediction. The proposed model is just a first simple step toward a better understanding of the interaction of social and risk preferences. In the paper we have proposed possible extensions and suggest some future research.

It has been shown that risk preferences relate to observable socio-demographic characteristics (see, e.g., Donkers et al. 2001; Dohmen et al. 2011; von Gaudecker et al. 2011). Therefore, our results, connecting risk preferences with giving, could be useful for policy makers and institutions as well as firms who benefit from knowing how pro-social behavior of different social groups responds to risks. In addition, our

\footnotetext{
${ }^{21} \mathrm{~A}$ screen shot of this task is provided in Section C of the ESM.
} 
results may be useful for organizations and individuals who have to make allocation decisions under risk. For instance, for charity organizations or individual researchers who have to raise funds, our evidence suggests that projects with high risk and high returns may be less successful in attracting funding than projects with a safer outlook.

We see large heterogeneity of behaviors in our experiments in both giving under certainty and giving under risk. When there is certainty, this may be accounted for by assuming heterogeneity purely in social preferences. Under risk, additional aspects enter the picture. For instance, in a previous paper we provide evidence that uninvolved individuals differ substantially in their views on what constitutes a just allocation under risk, even if they share the same view when there is certainty (Cettolin and Riedl 2017). It could be interesting to explore whether the large heterogeneity observed in the experiments reported here is also rooted in diverging views of justice under risk.

Open Access This article is distributed under the terms of the Creative Commons Attribution 4.0 International License (http://creativecommons.org/licenses/by/4.0/), which permits unrestricted use, distribution, and reproduction in any medium, provided you give appropriate credit to the original author(s) and the source, provide a link to the Creative Commons license, and indicate if changes were made.

\section{References}

Andersen, S., Harrison, G.W., Lau, M.I., \& Rutström, E.E. (2008). Eliciting risk and time preferences. Econometrica, 76(3), 583-618.

Andreoni, J., Aydin, D., Barton, B., Bernheim, B.D., \& Naecker, J. (2016). When fair isn't fair: Sophisticated time inconsistency in social preferences. Available at SSRN: https://ssrn.com/abstract=2763318.

Bardsley, N. (2008). Dictator game giving: Altruism or artefact? Experimental Economics, 11(2), 122133.

Bolton, G., \& Ockenfels, A. (2000). A theory of equity, reciprocity and competition. American Economic Review, 100(1), 166-193.

Bolton, G.E., Brandts, J., \& Ockenfels, A. (2005). Fair procedures: Evidence from games involving lotteries. The Economic Journal, 115(506), 1054-1076.

Broberg, T., Ellingsen, T., \& Johannesson, M. (2007). Is generosity involuntary? Economics Letters, 94(1), 32-37.

Brock, J.M., Lange, A., \& Ozbay, E.Y. (2013). Dictating the risk: Experimental evidence on giving in risky environments. American Economic Review, 103(1), 415-37.

Camerer, C.F. (2003). Behavioral game theory: experiments in strategic interaction. Princeton: Princeton University Press.

Cappelen, A.W., Hole, A.D., Sorensen, E., \& Tungodden, B. (2007). The pluralism of fairness ideals: An experimental approach. American Economic Review, 97(3), 818-827.

Cappelen, A.W., Konow, J., Sorensen, E., \& Tungodden, B. (2013). Just luck: An experimental study of risk taking and fairness. American Economic Review, 103(4), 1398-1413.

Cettolin, E., \& Riedl, A. (2017). Justice under uncertainty. Management Science, 63(11), 3739-3759.

Cherry, T.L., Frykblom, P., \& Shogren, J.F. (2002). Hardnose the dictator. American Economic Review, 92(4), 1218-1221.

Dana, J., Weber, R.A., \& Kuang, J.X. (2007). Exploiting moral wiggle room: Experiments demonstrating an illusory preference for fairness. Economic Theory, 33(1), 67-80.

Dimmock, S.G., Kouwenberg, R., \& Wakker, P.P. (2015). Ambiguity attitudes in a large representative sample. Management Science, 62(5), 1363-1380.

Dohmen, T., Falk, A., Huffman, D., Sunde, U., Schupp, J., \& Wagner, G.G. (2011). Individual risk attitudes: Measurement, determinants, and behavioral consequences. Journal of the European Economic Association, 9(3), 522-550. 
Donkers, B., Melenberg, B., \& Van Soest, A. (2001). Estimating risk attitudes using lotteries: A large sample approach. Journal of Risk and Uncertainty, 22(2), 165-195.

Ellsberg, D. (1961). Risk, ambiguity, and the Savage axioms. Quarterly Journal of Economics, 643669.

Engel, C. (2011). Dictator games: A meta study. Experimental Economics, 14(4), 583-610.

Engelmann, D., \& Strobel, M. (2000). The false consensus effect disappears if representative information and monetary incentives are given. Experimental Economics, 3(3), 241-260.

Fehr, E., \& Schmidt, K. (1999). A theory of fairness, competition and co-operation. Quarterly Journal of Economics, 114(3), 817-868.

Fischbacher, U. (2007). Z-tree: Zurich toolbox for ready-made economic experiments. Experimental Economics, 10(2), 171-178.

Forsythe, R.J., Horowitz, J., Savin, N., \& Sefton, M. (1994). Fairness in simple bargaining experiments. Games and Economic Behavior, 6(3), 347-369.

Fudenberg, D., \& Levine, D.K. (2012). Fairness, risk preferences and independence: Impossibility theorems. Journal of Economic Behavior \& Organization, 81(2), 606-612.

Gill, D., \& Prowse, V.L. (2012). A structural analysis of disappointment aversion in a real effort competition. American Economic Review, 102(1), 469-503.

Haisley, E., \& Weber, R. (2010). Self-serving interpretations of ambiguity in other-regarding behavior. Games and Economic Behavior, 68(2), 614-625.

Holt, C., \& Laury, S. (2002). Risk aversion and incentive effects. American Economic Review, 92(5), 1644-1655.

Kahneman, D., \& Tversky, A. (1979). Prospect theory: An analysis of decision under risk. Econometrica, 47(2), 263-291.

Kahneman, D., \& Tversky, A. (1991). Loss aversion in riskless choice: A reference-dependent model. Quarterly Journal of Economics, 106(4), 1039-1061.

Kőszegi, B., \& Rabin, M. (2006). A model of reference-dependent preferences. The Quarterly Journal of Economics, 1133-1165.

Krawczyk, M. (2010). A glimpse through the veil of ignorance: Equality of opportunity and support for redistribution. Journal of Public Economics, 94, 131-141.

Krawczyk, M.W. (2011). A model of procedural and distributive fairness. Theory and decision, 70(1), 111-128.

Krawczyk, M., \& Lec, F.L. (2010). 'Give me a chance!' An experiment in social decision under risk. Experimental Economics, 13(4), 500-511.

List, J. (2007). On the interpretation of giving in dictator games. Journal of Political Economy, 115(3), 482-493.

Mullen, B., Atkins, J.L., Champion, D.S., Edwards, C., Hardy, D., Story, J.E., \& Vanderklok, M. (1985). The false consensus effect: A meta-analysis of 115 hypothesis tests. Journal of Experimental and Social Psychology, 21(3), 262-283.

Neilson, W.S. (2006). Axiomatic reference-dependence in behavior toward others and toward risk. Economic Theory, 28(3), 681-692.

Rabin, M. (2000). Risk aversion and expected-utility theory: A calibration theorem. Econometrica, 68(5), $1281-1292$.

Rohde, I.M., \& Rohde, K.I. (2015). Managing social risks-tradeoffs between risks and inequalities. Journal of Risk and Uncertainty, 51(2), 103-124.

Saito, K. (2013). Social preferences under risk: Equality of opportunity versus equality of outcome. The American Economic Review, 103(7), 3084-3101.

Schlag, K.H., \& der Weele, J.J. (2015). A method to elicit beliefs as most likely intervals. Judgment and Decision Making, 10(5), 456.

Trautmann, S. (2009). A tractable model of process fairness under risk. Journal of Economic Psychology, $30(5), 803-813$.

von Gaudecker, H. -M., van Soest, A., \& Wengstrom, E. (2011). Heterogeneity in risky choice behavior in a broad population. American Economic Review, 101(2), 664-94.

Wakker, P. (2008). Explaining the characteristics of the power (CRRA) utility family. Health Economics, 17(12), 1329-1344. 